\title{
Escuela Normal de Costa Rica: Historia y legado
}

\section{Escuela Normal (Normal School) of Costa Rica: History and Legacy}

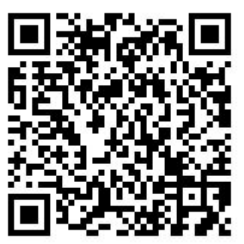

\author{
Vivian Carvajal-Jiménez ${ }^{1}$ \\ Universidad Nacional \\ Heredia, Costa Rica \\ vivian.carvajal@gmail.com \\ Silvia Ruiz-Badilla² \\ Universidad Nacional \\ Heredia, Costa Rica \\ silviacostarica@gmail.com
}

Recibido 16 de setiembre de 2015 • Corregido 30 de octubre de 2015 • Aceptado 17 de noviembre de 2015

Resumen. En el marco del centenario de la Escuela Normal de Costa Rica, este documento discute su rol y legado en la formación docente. Se estructura en tres partes. En primer lugar, se presenta una breve contextualización histórica sobre el origen y perfil de las escuelas normales en varias partes del mundo. En segundo lugar, se describe el desarrollo de la Escuela Normal en Costa Rica, se referencian varias personalidades y elementos significativos que marcaron el rumbo y prestigio de la institución, y se destaca su papel clave en la formación humanista de maestros, la cual contribuyó a cimentar el florecer educativo costarricense. Finalmente, se presentan algunas consideraciones sobre los remanentes del legado formativo de esta noble institución en el presente, concretamente en el ámbito de la educación terciaria, en las carreras de formación docente de la Universidad Nacional, principal heredera histórica de la Escuela Normal.

Palabras claves. Formación docente, Escuela Normal, Universidad Nacional.

Abstract. On the centennial of the Escuela Normal (Normal School) of Costa Rica, this paper discusses its role and its legacy in teacher training. It is structured in three parts. Firstly, it presents a brief historical background of the origin and profile of normal schools in various parts of the world. Secondly, it describes the development of the Escuela Normal (Normal School) in Costa Rica, refers to various personalities and significant elements that have set the course and prestige of the institution, and places the emphasis on its key role in the humanistic training of teachers, which helped to establish the foundations of Costa Rican educational development. Finally, it presents some remarks about the educational legacy of this noble institution that has remained to this day, particularly in tertiary education, in the teacher training career at the National University, the major historical heir of the Escuela Normal (Normal School).

Keywords. Teacher training, Normal School, National University.

\footnotetext{
${ }^{1}$ Académica en la División de Educación Rural de la Universidad Nacional.

${ }^{2}$ Académica en la División de Educología de la Universidad Nacional.
} 
doi: http://dx.doi.org/10.15359/ree.20-1.21

URL: http://www.una.ac.cr/educare

CORREO: educare@una.cr

La educación y la formación de maestros y maestras, indiscutiblemente, constituyen un tema de vital importancia en todo el mundo. De manera particular, desde finales del siglo XX, numerosos acuerdos internacionales y congresos de todo el orbe han postulado la formación docente como un asunto prioritario. Esto lleva a posicionar este tema en las agendas del país y, por consiguiente, a plantear interrogantes vinculadas con la formación terciaria y su pertinencia para la profesionalización docente.

En el caso costarricense, a 100 años del surgimiento de la Escuela Normal, y aunque hace décadas la formación de docentes está en mano de las universidades, es innegable que para consolidar una formación humanista que atienda las demandas de la sociedad y de los grupos en mayor desventaja social, resulta imperativo recurrir a la historia y rescatar las bondades de diversos sistemas de formación, particularmente de aquellos que resultaron exitosos e innovadores. En este sentido, la Escuela Normal surge siempre como un emblema significativo al evocar los orígenes de la formación docente en Costa Rica.

La Escuela Normal, su legado y cómo este se materializa y cobra vigencia en la formación docente de nuestros días -en particular en la Universidad Nacional, principal heredera del quehacer de aquella institución-, es un tema que reclama protagonismo al enfrentar los actuales paradigmas formativos con las necesidades del presente. Precisamente, este texto recorre los orígenes de esta institución y su legado a la formación de maestros y maestras de nuestros días. A continuación, una síntesis alrededor de estas cuestiones.

\section{Escuelas normales: orígenes y perfil}

Tras las guerras napoleónicas y la reestructuración social que estas acarrean en toda Europa, se inicia una reconfiguración de la escuela y de los ámbitos que esta entraña, dado que los estados europeos asumen el control de los sistemas escolarizados dirigidos a la población infantil y, por tanto, de la formación de docentes, que se pregona entonces desde una óptica innovadora y moderna (Escolano, 1982).

La configuración de estas instituciones está estrechamente vinculada con el periodo de la llustración francesa y sus proyectos educativos, con el reconocimiento de la educación como un derecho fundamental, los movimientos de educación popular y con la valoración de esta como un elemento de apoyo a los nacionalismos y al orden liberal-burgués que recién surgía (Escolano, 1982); lo que obviamente, posiciona a las escuelas normales como aliadas en la promoción o en el adoctrinamiento de proyectos ideológicos concretos.

En este sentido, Dengo (2013) menciona que "la Escuela Normal como institución es una creación del siglo XIX... en el contexto de la Revolución Francesa" (p. 203), época en la que existía preocupación por: 
La falta de competencia de quienes enseñaban... para trasmitir los conocimientos necesarios con el debido método, para promover la capacidad de raciocinio de los alumnos y para adaptarse a las necesidades psicológicas de estos, por lo que [se] señaló la urgente necesidad de formar un nuevo tipo de maestro, preparado específicamente para ello. (Dengo, 2013, p. 203)

Asimismo, movimientos como las escuelas mutuas (Gran Bretaña) ${ }^{3}$ y los métodos pestalozzianos ${ }^{4}$ en el centro de Europa contribuyeron a perfilar las primeras acciones formativas y estatales dirigidas a docentes.

En Rusia, por ejemplo, se tienen datos de la existencia de 40 escuelas normales para 1800. De Prusia se sabe de la presencia de este tipo de casas formadoras para 1828. Por su parte, en Francia se abrieron 11 escuelas normales en 1829. En los Estados Unidos la primera normal school se funda en Massachusetts en 1837, y para 1875 en Bélgica existían ya 40 escuelas normales (Escolano, 1982).

En América Latina, las escuelas normales como centros de formación docente datan incluso de antes de mediados del siglo XIX. Así, Perú organiza su primera escuela normal de varones en 1822, mismo año en que México abre su primera instancia de este tipo (Salgado, s. f.), mientras que Chile, inspirada en el modelo europeo, abre las puertas de la primera institución formadora de maestros en 1842 (Núñez, 2010). Según Núñez (2010), antes de la creación de esa instancia, las escuelas primarias eran escasas y sus condiciones eran lamentables, con docentes que carecían de formación alguna para ejercer su tarea.

Al igual que en Europa, en Latinoamérica estas instituciones reciben una fuerte influencia de grupos moralizantes, por lo que las primeras escuelas normales destacan por su disciplina y costumbres (Escolano, 1982; Núñez, 2010). Lo cierto del caso es que a partir de la creación de la escuela normal chilena, el modelo continúa reproduciéndose por el resto del mundo latino, replicando en su mayoría los postulados y principios que vieron nacer la institución en el continente europeo, toda vez que la realidad en nuestro continente era distinta y que, en la práctica, sería la coyuntura social la que finalmente se impondría para perfilar la escuela normal latinoamericana.

\footnotetext{
${ }^{3}$ La escuela o enseñanza mutua se vincula con la revolución industrial y las precarias condiciones de los obreros. Consistió básicamente en una estrategia para alfabetizar a las masas, inspirada en las ideas de la revolución francesa (Charconnet, 1975).

${ }^{4}$ Pestalozzi fue un pedagogo suizo que revoluciona el sistema educativo a partir del principio de que la inteligencia es posible mediante la percepción espontánea. Sus ideas influyeron en las escuelas de todo el continente europeo y se cree que han contribuido al desarrollo de la pedagogía en todo el mundo. El principal objetivo de Pestalozzi fue adaptar la enseñanza al desarrollo natural de la niñez, que debía aprender de sus propias experiencias.
} 
doi: http://dx.doi.org/10.15359/ree.20-1.21

URL: http://www.una.ac.cr/educare

CORREO: educare@una.cr

De esta forma, Argentina funda su primera escuela normal en 1870, seguida por Colombia; Uruguay inicia con la normal en 1885 y Ecuador abre la institución de varones en 1889. Por su parte, Bolivia inaugura una escuela normal en 1909. Para República Dominicana será 1863, y para Cuba, 1959.

En Centroamérica, El Salvador cuenta con una escuela normal desde 1832, Honduras desde 1836, Guatemala la inaugura en 1875 y Panamá en 1872 (Salgado, s. f.). Por su parte, Nicaragua funda la primera Escuela Normal de Señoritas de la región en 1908; y Costa Rica le sigue en 1914; aunque 100 años antes ya Costa Rica contaba con un centro formativo de educadores: la Casa de Enseñanza Santo Tomás.

Investigadores como Núñez (2010) señalan que la configuración de las escuelas normales latinoamericanas se desarrolla en distintos momentos. Así, se marca un primer periodo de poco más de cuatro décadas, entre 1842 -con la apertura de la normal chilena- y 1885; donde era evidente la influencia de un modelo mucho más moralista que pedagógico; pues si bien se decía quela formación apuntaba hacia la idoneidad docenteen el sentido de su experticia metodológica, era claro que "...la dimensión pedagógica fue la pariente pobre de la formación normalista" (p. 34). Desde luego, la moral que propagaban esos primeros esfuerzos por profesionalizar el ejercicio docente, no era sino un reflejo de los prejuicios, la ideología dominante, la religiosidad oficial y los intereses políticos que predominan entre las clases pudientes:

Los "civilizadores" de la masa popular tenían que ser civilizados ... la primera normal -y las siguientes- se convirtió en un internado con fuerte y desmedido sentido disciplinante.. A esto se sumaban también los requisitos de ingreso y las prácticas selectivas que sostenían las normales ... en que la moralidad y buenas costumbres de las familias de origen y el comportamiento del alumno en la escuela, determinaban su trayectoria. (Núñez, 2010, p. 35)

Posteriormente, un segundo momento se evidencia en la evolución normalista latinoamericana entre 1885 y 1928. Durante este lapso se hace notaria la influencia alemana, pues es frecuente que profesores germanos y austríacos visiten las normales, especialmente en Chile, y que docentes de las normalistas viajen también a prepararse a "los países más avanzados" (Núñez, 2010, p. 36). Asimismo, se importaron tendencias estadounidenses, lo que deja en claro que la realidad, el contexto local y las necesidades de la región, pasaron a un segundo plano en términos de configurar un modelo pedagógico pertinente a esta parte del mundo.

De acuerdo con Salgado (s. f.), el normalismo latinoamericano de esa época se caracterizó por la presencia de misiones extranjeras que usualmente eran invitadas por el gobierno de turno, dado el interés de introducir nuevos modelos pedagógicos; sin embargo, fue recurrente también la participación de órdenes religiosas, lo que resulta coherente con un modelo todavía moralizante. 
Para esta época, además, la escuela normal latinoamericana presentaba rasgos como los siguientes (Núñez, 2010):

- La enseñanza normalista se subordina dentro del sistema escolar, ya que, aunque se trataba de un nivel postprimario, su conclusión no permitía continuar con estudios superiores en una universidad.

- La instrucción (idoneidad) y el disciplinamiento (moralidad) fueron sellos de la actividad normalista inclusive durante todo el siglo XX.

- Sus dependencias estaban al servicio de los ministerios de educación o instrucción, y en muchos casos, adscritas a estos.

- Poco eficiente para suplir la totalidad de maestros y maestras que la realidad demandaba, pues pese a la existencia de las normales, siguió siendo abrumadora la cantidad sin título.

- La formación poseía carácter enclaustrado: normalistas debían formar a normalistas.

- El que una persona iniciara estudios en la normal era indicador de que empezaba en el aparato estatal y que "tenía por delante décadas de vida como empleado" del gobierno, con salarios limitados y escaso prestigio profesional (Núñez, 2010, p. 37).

- Su régimen era, en muchos casos, de internado, con gastos asumidos por el gobierno, lo que fue cambiando paulatinamente en el siglo XX, con el ingreso de alumnado externo.

Es importante anotar que al finalizar este segundo período, concretamente en 1927 y 1928, en algunos países de la región se da un movimiento contestatario entre docentes, quienes en gremios, lanzan una propuesta de reforma integral inspirada en la Escuela Nueva ${ }^{5}$.

Entre 1929 y 1967 se da el tercer momento en la evolución del modelo normalista, donde se refuerzan las regulaciones de carácter uniformante y se debilita el internado. Asimismo, se empieza a tender, tímidamente, hacia la diversidad, al ingresar estudiantes de zonas rurales y mujeres. A estos cambios se suman el empobrecimiento del aporte estatal y la imperante demanda de docentes, que hace que se generen procesos acelerados de formación.

Finalmente, la cuarta fase se da entre 1967 y 1973, tiempo en el que se abandona el modelo normalista conocido hasta entonces y, en varios países, pese a mantener la estructura institucional, las normales se convierten en instancias postsecundarias de educación superior no universitaria.

Sin duda, durante más de 130 años las escuelas normales contribuyeron con el fortalecimiento de sociedades más letradas, donde muy lentamente se inicia el acceso a la educación de grupos tradicionalmente excluidos del sistema. Por supuesto, esta formación se

${ }^{5}$ Conjunto de principios que surgen a finales del siglo XIX en Europa, y se consolidan en el primer tercio del siglo XX como alternativa a la enseñanza tradicional. 
doi: http://dx.doi.org/10.15359/ree.20-1.21

URL: http://www.una.ac.cr/educare

CORREO: educare@una.cr

dio en correspondencia con los cánones de la época y de la mano con las premisas de lo que en aquellos años se consideraba "correcto". No obstante, la formación de entonces ya se perfilaba como un proceso de entrenamiento de al menos seis años, donde se constituye una suerte de identidad entre quienes participan de este.

Así, Maya y Zenteno (2003) refieren que la escuela normal no es sino un signo de lo acontecido en el mundo, dado que en la mayoría de países donde el modelo se afianza, este se vincula con momentos históricos clave que se sostienen en los avances y logros de la educación pública en la región, de lo que resulta su protagonismo en la configuración cultural y social.

Para Salgado (s. f.), es innegable el hecho de que durante la mayor parte del siglo XX las escuelas normales en América Latina constituyen una poderosa herramienta de movilidad social, puesto que gran cantidad de jóvenes de estratos sociales bajos acceden a ellas. Este autor destaca que, en mayor o menor medida, en algunos países de la región la formación docente estuvo marcada por el militarismo y la dictadura. Este hecho es clave, ya que incluso en algunos casos las escuelas normales fueron clausuradas por razones políticas, y en otros, sus estudiantes fueron trasladados a universidades, pasando de una formación secundaria a terciaria.

Para los autores mencionados anteriormente (Maya y Zenteno, 2003; Salgado, s. f.), ante el advenimiento de la globalización, los avances científicos y tecnológicos, así como el cuestionamiento de los paradigmas convencionales, las políticas educativas se diversifican en torno a un discurso orientado a la calidad de la educación, que necesariamente permea el quehacer de las escuelas normales en la región.

Ante este contexto, principalmente a partir de la década del 70, muchos países cambian el modelo de formación de maestros y maestras en escuelas normales, y pasan a la constitución de institutos o universidades pedagógicas, o bien, a la conformación de facultades pedagógicas que se adscriben a una universidad (Salgado, s. f.).

Para Figueroa (2000), en tiempos modernos la formación docente y la profesionalización en las escuelas normales es motivo de profundos debates, a pesar de que es notoria la visión interdisciplinaria y la identidad profesional que se construye alrededor de las escuelas normales como instancias de formación en el nivel secundario o preuniversitario. Esta formación, vista como tarea estatal, es una de las más atendidas por las políticas educativas, por lo que las transformaciones que sufren las escuelas normales a lo largo de su existencia se relacionan de forma directa con los cambios sociales y contextuales. En palabras de Figueroa (2000):

La formación que se ofrece en las escuelas normales se ha caracterizado por tender a homogenizar prácticas y discursos. Tales discursos y prácticas se apegan a modelos metodológicos únicos que la modernidad ha implantado. Buscar la receta de cómo ser maestro parece ser la tónica del enfoque positivista... El cómo pensar la formación y sus 
estrategias ha sido prioridad para diversos actores... Resultado de ello son los modelos construidos... que se caracterizan por un mayor énfasis en los aspectos técnicos que en los teóricos. Además de ese énfasis en los espacios de las escuelas normales se puede observar la importancia... [de] la planeación, mayor que cualquier otro acontecimiento académico en la vida cotidiana de éstas.

La tensión que se genera entre el deber ser y el ser es una de las cuestiones más difíciles de resolver; sin embargo, en el discurso se plasman perfiles demasiado idealizados, a sabiendas que ser maestro no es cuestión de definiciones operativas... (Figueroa, 2000, p. 120)

A esta idealización del personal docente se debe sumar el innegable lazo que existe entre la desaparición o transformación de las normales y los cambios políticos que se dan en América Latina. Es consistente en toda la región la supresión o arrinconamiento de normalistas y profesorado que les formaban -casi siempre personas pensadoras destacadas-, con el inicio de dictaduras o revoluciones. Incluso hasta nuestros días, pese a que el discurso y el modelo normalista se ha caracterizado por su tono moralizante y adoctrinador, en distintos espacios y países del continente, los grupos normalistas han sido perseguidos por su postura contestaria y desafiante.

\section{La Escuela Normal de Costa Rica}

Los precedentes de la educación normal en Costa Rica se remontan a mediados del siglo XIX, cuando se fijan las bases para una escuela normal, mediante un decreto emitido el 13 de noviembre de 1840 por el doctor José María Castro Madriz (Cordero, 1998). Para ese tiempo, surge la preocupación por darle al maestro o maestra la formación específica necesaria para responder a los procesos de educación elemental que se desarrollaban en el país. No obstante, ya en 1814 se abre la Casa de Enseñanza de Santo Tomás, que luego, en 1843, fue convertida en universidad.

Con el decreto del doctor Castro Madriz, en 1840 se establece una escuela normal exclusiva para varones, y en 1849 el Liceo para Niñas, un centro de educación media con carácter normal.

En la segunda mitad del siglo XIX, debido a los intereses de ampliar y mejorar la educación pública, se fundan otras escuelas normales en el centro del país, entre las cuales están las integradas al Liceo de Costa Rica y al Colegio Superior de Señoritas, creadas por Mauro Fernández en 1887 y 1888, respectivamente. Según Hernández y Lobo (1996), estos centros funcionaban como escuelas modelo donde se establecieron "las bases técnico pedagógicas de la formación docente como profesión" (p. 5), debido a que en ellas "se impartían cursos, conferencias, exámenes para maestros, políticas de inspección y asesoramiento" (p. 5). Esta división de las secciones normales en escuelas para varones y para niñas se había institucionalizado y dominó durante las últimas décadas del siglo XIX e inicios del XX (Solera, 1965). 
doi: http://dx.doi.org/10.15359/ree.20-1.21

URL: http://www.una.ac.cr/educare

CORREO: educare@una.cr

Precisamente, para esta misma época, en Costa Rica existía una gran necesidad de formar docentes que atendieran la expansión del sistema escolar nacional, especialmente en el nivel de primaria, lo que explica la apertura de las diversas secciones normales.

Conforme la profesión docente adquiere relevancia y prestigio social, comienza a ser urgente contar con "una verdadera escuela normal" (Dengo, 2013, p. 217) que formara a los maestros requeridos para nuestro territorio. A inicios del siglo XIX, por ejemplo, más del 80\% de los maestros y maestras en servicio carecía de titulación o certificación de aptitud para la docencia (Dengo, 2013).

En general, en el país se dieron varios intentos para afianzar una formación normalista, muchos de los cuales se concretaron en las diversas secciones e instituciones que brindaban cursos pedagógicos para la formación docente, pero de manera efímera. La enseñanza normal llega a su cúspide con la creación de la Escuela Normal de Costa Rica y se vigoriza aún más con el establecimiento de escuelas normales en otras provincias y zonas rurales.

La Escuela Normal de Costa Rica fue creada mediante el decreto número 10, el 28 de noviembre de 1914, durante el mandato presidencial de Alfredo González Flores, apoyado por su hermano Luis Felipe González Flores, quien en ese momento estaba a cargo del Despacho de Instrucción Pública. Debido a la carencia de un terreno y edificio propios, González Flores ordena utilizar el espacio y los planos que se tenían destinados para el Liceo de Heredia, para establecer en su lugar la Escuela Normal. Sin embargo, el primer curso lectivo en esta institución inicia en abril de 1915, en la Escuela Braulio Morales, mientras se finiquita la construcción del nuevo plantel. Cinco meses después, la institución se traslada al recién construido edificio, donde permaneció hasta 1956 (Meléndez, 2001).

Con la creación de la Escuela Normal de Costa Rica, los estudios docentes de las secciones pertenecientes al Liceo de Costa Rica y al Colegio Superior de Señoritas son trasladados a ese centro educativo $y$, desde ese momento, la formación de maestros y maestras se desprende principalmente de esta institución.

Según Dengo (2013), con el establecimiento de la Escuela Normal, se buscaba "introducir un nuevo proceso socioeconómico en el país [y] ubicar la educación dentro de las corrientes sociales y científicas en boga y reforzar su capacidad democrática; ... con la formación docente como estrategia clave (p. 221)".

Además, con esta nueva institución se daba respuesta a la "convicción... del verdadero carácter, dentro de un nuevo concepto, de lo que debía ser una institución formadora de docentes: es decir, una Escuela Normal en el amplio y mejor sentido, y no una sección" (Dengo, 2013, p. 222). 
Don Arturo Torres fue el primer director de la Escuela Normal. Su nombramiento se dio "en forma interina y en calidad de recargo" (Hernández y Lobo, 1996, p. 13). Bajo su dirección, en la primera graduación, que tuvo lugar en noviembre de 1915, se graduaron 20 personas y se estrenó "Alma Mater", el himno oficial de la Normal.

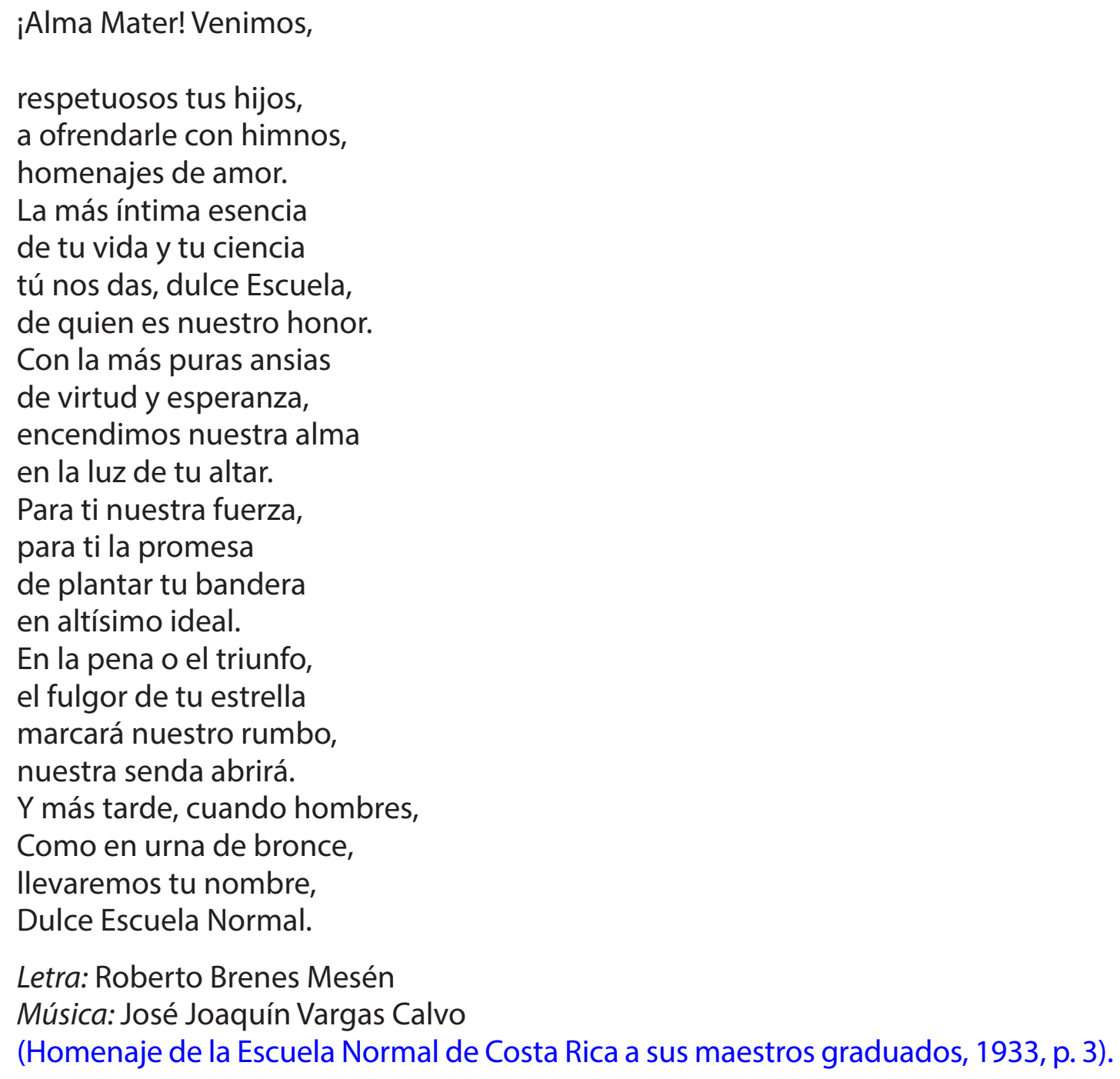

La letra de este himno fue escrita por Roberto Brenes Mesén, y su música compuesta por José Joaquín Vargas Calvo, ambos profesores de la Escuela Normal, evidencia de que, en el caso de Costa Rica, eran docentes ilustres y de gran bagaje cultural quienes tenían la responsabilidad de la formación de maestros y maestras. 
doi: http://dx.doi.org/10.15359/ree.20-1.21

URL: http://www.una.ac.cr/educare

CORREO: educare@una.cr

En Alma Mater, pieza oficial y emblema de la Escuela Normal, se resalta el respeto, la admiración, la estima y el agradecimiento por la "vida" y la "ciencia", sentidos por el personal que ahí se formaba; además, el compromiso y la entrega que con ansias y esperanzas pudieron sentir por su Escuela. Al final del himno, se expresa el compromiso de atesorar y llevar consigo el nombre de la institución.

Estos sentimientos de entrega, respeto, fidelidad y admiración por la institución, no solo se evidenciaban en la letra del himno, sino en el actuar y en el ejercicio profesional de su personal graduado. Al respecto, Hernández y Lobo (1996) afirman que la influencia que la Escuela Normal de Costa Rica tuvo en la vida "profesional, espiritual, cultural, social y humana de sus alumnos" es innegable (p. 1).

Al comienzo, la preparación que se daba en la Normal estaba conformada por cursos generales y educacionales, tal y como correspondía con el segundo momento evolutivo de estas instituciones. Entre los estudios generales destacaban: caligrafía, canto, ciencia sanitaria, cocina, costura, dibujo, estudio de la naturaleza y agricultura, geografía, geología y mineralogía, historia y administración pública, inglés o francés, juegos escolares, literatura castellana, literatura infantil, lógica y debate, matemáticas y métodos, práctica escolar, psicología de la educación, sociología educacional, y trabajos manuales; todos caracterizados por su enfoque humanista, que si bien hoy nos resulta revelador como parte del currículo formador de docentes, debe contextualizarse también en cuanto al papel que suponía en la época, pues en la secundaria (que no cursaban normalistas), como se mencionó anteriormente, se daba también este tipo de enfoque humanista. Por su parte, los cursos educacionales estaban constituidos por administración escolar, agricultura y jardinería escolar, dibujo en el encerado, extensión escolar, higiene escolar, historia y principios de educación, historia de la educación nacional, legislación escolar, práctica en ramas especiales, preparación de material escolar, y práctica escolar, esta última de mayor prioridad curricular (Homenaje de la Escuela Normal de Costa Rica a sus maestros graduados, 1933; Hernández y Lobo, 1996).

La preparación se dividía en tres secciones: 1) Sección de Estudios Generales, cuyo objeto era preparar a sus estudiantes en los tres primeros años de la segunda enseñanza, 2) Sección Normal, que constaba de tres años dedicados a la preparación profesional, y 3) Sección Escuela de Aplicación, que constaba de cinco años de práctica de enseñanza primaria (Homenaje de la Escuela Normal de Costa Rica a sus maestros graduados, 1933). Estas prácticas se realizaban con la supervisión de personal tutor y tenían lugar en la Escuela de Aplicación. En Heredia, por ejemplo, cuando abrió la Escuela Normal, los futuros maestros y maestras hacían prácticas en la que fuera la Escuela República de Argentina, que en aquellos años se conoció primero como Escuela de Aplicación y más tarde como Escuela de Aplicación República de Argentina (Meléndez, 2001). 
Es notorio que el enfoque humanista que atravesaba la formación docente en la Normal estaba teñido por el arte y la cultura, de ahí que muchos de los profesores y profesoras de entonces sean recordados en la historia costarricense como artistas, mujeres y hombres de cultura. Este hecho tiene que haber marcado profundamente las generaciones que estudiaron en esta institución, y por supuesto, a los cientos de niños y niñas que luego pasaron por las aulas de esos maestros y maestras: se formaba para apreciar el arte, la cultura, la literatura y la música. A esto, se suma la relevancia que ya se le daba al juego como parte del currículo, lo que supone una formación lúdica orientada hacia concebir los espacios de educación formal como oportunidades donde la niñez aprendiera de forma grata y desde su naturaleza y necesidades.

La mayor parte de la población estudiantil de la Escuela Normal pertenecía a la clase humilde costarricense. Muchos de ellos, en especial quienes provenían de zonas alejadas, recibían ayuda mediante un sistema de becas. Es importante señalar que, durante ese tiempo, "la enseñanza era una de las pocas opciones profesionales para quienes deseaban estudiar, en particular [para] las mujeres. Por otra parte, el título de maestro Normal abría la posibilidad de ingresar en la Escuela de Derecho y alcanzar de esta forma el más alto status académico" (Hernández y Lobo, 1996, pp. 43-44). Así, la Escuela Normal significaba para sus graduados un medio para la trasformación cognitiva, social y económica.

En el período 1917-1919, por la situación económica y política del país, acentuada por el golpe de estado de Federico Tinoco, los intereses de orden político privan sobre los educativos, por lo que se reprime y censura al personal administrativo y docente de la Escuela Normal que fuera discrepante con el Gobierno. Como consecuencia, se despide a un gran número de sus docentes, se dan cambios en la administración de la Escuela, el personal de la institución es nombrado en estado de interinazgo, se disminuye el número de becas, se repatria estudiantado becado y varios profesores normalistas dejan de ejercer la docencia (Fischel, 2013). Además, según las notas de don Felipe González, la Escuela Normal se tuvo que reestablecer en San José y depender más de la Secretaría de Guerra y menos de la Secretaría de Educación (Homenaje de la Escuela Normal de Costa Rica a sus maestros graduados, 1933).

Como se anotó párrafos atrás, en la historia de las normales no ha sido extraña la represión política. Tal parece que la formación que se desarrollaba en el seno de estas instituciones, a cargo de activistas, personajes de la cultura y la política, y otras figuras de renombre ${ }^{6}$, superaba por mucho el modelo pedagógico que oficialmente se imponía. En palabras de Fischel (2013), para ese tiempo, la Escuela Normal:

\footnotetext{
${ }^{6}$ Entre ellos Máximo Blanco, Omar Dengo y Emma Gamboa.
} 
doi: http://dx.doi.org/10.15359/ree.20-1.21

URL: http://www.una.ac.cr/educare

CORREO: educare@una.cr

...se había convertido en un centro de estudios políticos y pedagógicos de avanzada. Si bien la mayoría de los educadores impartía clases en secundaria, se reunían en "la Normal" para discutir sobre diferentes corrientes de pensamiento, que oscilaban desde el esoterismo hasta el pragmatismo. Estos análisis intelectuales no eran solamente de corte académico sino también involucraban un cuestionamiento crítico del sistema social establecido y de los privilegios de los grupos dominantes. (p. 94)

Evidencia de lo anterior, fue la manifestación nacional contra el gobierno dictatorial de los Tinoco ${ }^{7}$ dirigida por la profesora normalista y escritora María Isabel Carvajal (Carmen Lyra).

En 1919, recién establecido el nuevo Gobierno Constitucional, Omar Dengo Guerrero asume la Dirección de la Escuela Normal. Durante su período como director, reorganiza el personal docente y se empeña en mejorar el nivel cultural de la institución. Además, entre sus acciones, propone modificar el plan de estudios y reducir las tres secciones en dos: la Preparatoria y la Normal.

La Sección Preparatoria comprendía los siguientes cursos:

Lengua materna, inglés, matemática, física, química, ciencias naturales, geografía, historia, higiene, aritmética comercial, caligrafía, música, dibujo, agricultura, trabajos manuales, cocina, costura y economía doméstica". La Sección Normal, por su parte, constaba de los siguientes: "literatura, inglés, francés, matemáticas, física y química, ciencias naturales, historia, geografía, elementos de administración pública, psicología y lógica, anatomía, fisiología, higiene y enfermería, pedagogía, higiene escolar, preparación de material de enseñanza, historia de la educación, historia de la educación nacional, psicología educacional, paidología, psicología de los ramos de educación primaria, sociología general y educacional, administración y legislación escolares, práctica de enseñanza, trabajos manuales, música, dibujo, educación física, agricultura, costura y cocina. (Homenaje de la Escuela Normal de Costa Rica a sus maestros graduados, 1933, p. 8-9)

En la Escuela Normal los asuntos educacionales constituyeron una prioridad, sus directores velaron porque así fuera y se preocuparon por estar a la vanguardia de las técnicas y métodos más novedosos. Sin embargo, no todo quedó en la técnica y el sistema educacional, pues la institución tenía fama por su espíritu social y era reconocida como el lugar donde se formaban maestros y maestras de primaria amantes y conscientes de la responsabilidad que implicaba su profesión. En palabras de Cordero (1998), la Normal se constituía en "un plantel de educación

\footnotetext{
${ }^{7}$ No obstante, la peor represión para Carmen Lyra vino mucho después, en 1948. Durante el gobierno de don Julio Acosta, Carmen Lyra viajó a Europa para realizar estudios pedagógicos, y allí se empapó de ideas comunistas; de hecho, María Isabel tradujo al español el Manifiesto comunista. Fue luego de la revolución armada del 48, cuando José Figueres Ferrer expulsó del país a comunistas cuando María Isabel fue exiliada a México.
} 
especial dedicado a la preparación de maestros idóneos para dirigir las escuelas primarias oficiales del país" (p. 30). De esta afirmación se desprende que la idoneidad docente, como característica de la formación normalista latinoamericana, tenía vigencia también en Costa Rica.

El espíritu social que identificaba la Escuela Normal fue infundido principalmente por sus directores, entre los cuales destacó don Arturo Torres, para quien los maestros y maestras debían cumplir con la función social y política de ser líderes de la democracia. Otros directores, como Roberto Brenes Mesén y Joaquín García Monge, quienes ocuparon sus cargos en 1916 y 1917-1918, respectivamente, mantuvieron el mismo sentir:

Continuaron el mismo espíritu... inspirando la labor en la parte educacional, en el espíritu social de la Escuela, en la modernidad de los sistemas y métodos pedagógicos y en la comprensión de la función social del maestro de la enseñanza primaria, haciendo sentir en los alumnos la responsabilidad que aquella función entraña. (Homenaje de la Escuela Normal de Costa Rica a sus maestros graduados, 1933, p. 7-8)

Aparte de estos reconocidos directores, la Escuela Normal contó con otros personajes importantes en el cargo: Carlos Gagini, Juan Dávila, Carlos Luis Sáenz y Hernán Zamora Elizondo. Todos ellos impregnaron y desarrollaron el espíritu social de la institución mientras la dirigieron. Para Solera (1965), los directores "fueron los pioneros de la mística que envolvió a la Escuela e inundó los ámbitos de la educación nacional" (p. 30). Indudablemente, esta tarea fue acompañada y fortalecida por el cuerpo docente de la institución, entre este grupo: Luis Dobles Segreda, José Joaquín Vargas Calvo, Samuel Sáenz Flores, Juan Ramón Bonilla, Carlos Luis Sáenz, Adela Ferreto, Angélica Gamboa y María Isabel Carvajal (Dengo, 2013).

En general, la Escuela Normal de Costa Rica impregnó de:

Un verdadero sentido a la enseñanza primaria con la mejora de los sistemas, métodos, vinculación de la enseñanza a los problemas nacionales y con él [sic] constante afán de hacer del maestro un verdadero profesional significando cada vez más la función social y política del educador. (Homenaje de la Escuela Normal de Costa Rica a sus maestros graduados,1933, p. 13)

Meléndez (2001), quien experimentó de cerca la influencia de esta institución, como graduado primero y como docente después, afirma:

No es posible sintetizar siquiera lo que, la Escuela Normal ha significado en la vida cultural de la ciudad y del país. Debe recordarse que no existía entonces la universidad y que la Escuela Normal hizo entre 1915 y 1941 sus veces. La calidad de los docentes, el hecho de que viniesen de todo el país estudiantes y la mística que allí existió, constituyen quizás tres de los rasgos más sobresalientes de esta institución educativa (p. 63). 
doi: http://dx.doi.org/10.15359/ree.20-1.21

URL: http://www.una.ac.cr/educare

CORREO: educare@una.cr

En este sentido, a la Escuela Normal le correspondía ocupar el puesto supremo y de vanguardia en la formación de maestros y maestras en Costa Rica, no solo por la cantidad de grupos egresados, sino también por la calidad de maestros y maestras que en ella se formaban (Chaves, citado por Hernández y Lobo, 1996).

De acuerdo con Dengo (2013), después de los años 40 ocurre una serie de hechos que afectan la Escuela Normal y concluyen en su paulatina desaparición:

- En 1940, con la creación de la Universidad de Costa Rica (UCR), se establece la Escuela de Pedagogía, que absorbe la Sección Normal. En sus inicios, la Escuela de Pedagogía se ubica en Heredia, a la par de la Escuela Normal, pero años más tarde es trasladada a San José, donde, en 1956, se transforma en Facultad de Educación. La formación de docentes para la enseñanza secundaria también inicia, de forma sistemática, cuando se crea la UCR, pero a cargo de unidades académicas distintas a la Escuela de Pedagogía.

- En 1950, la Escuela Normal, con un modelo de educación superior, pasa de nuevo a Heredia, y en conjunto con la Escuela de Pedagogía y demás escuelas normales que existían en el país, se encargaron de la formación de docentes para primaria por varios años más.

- En 1967 comienza a funcionar una Sección de la Escuela Normal de Heredia, conocida como Escuela Normal Superior, que se dedicaría a la formación de docentes para la enseñanza media. Esta sección cerró sus puertas en 1973, cuando se creó la Universidad Nacional (UNA); específicamente porque la Normal Superior -junto con otras instituciones de formación docente- fue absorbida por la Escuela de Educación, que más tarde pasa a ser el Centro de Investigación y Docencia en Educación (CIDE), instancia que aún funciona.

Como se aprecia en estos últimos datos, la herencia histórica de la Normal es compartida entre el CIDE de la Universidad Nacional y la Facultad de Educación de la UCR, ambas "en obligada gratitud filial, deben hoy reconocer la fuente remota de donde proceden, la augusta Escuela Normal de Costa Rica" (Cordero, 1998, p. 33).

\section{Legado formativo de la Escuela Normal: consideraciones finales}

La Universidad Nacional, heredera del quehacer que antaño estuvo a cargo de la Escuela Normal, se resignifica como casa formadora de profesionales en las más amplias ramas del saber, y en esa línea, ha procurado reconocerse como una entidad comprometida socialmente; así lo expresa Rivera (2012): 
La Universidad Nacional... ha permitido ampliar y fortalecer la autonomía universitaria, impulsar el proceso de democratización de la educación superior estatal alentando el crecimiento y la expansión del sistema universitario. Además, esta casa de estudios ha permitido un mayor acceso al nivel superior ofreciendo una educación integral a los estudiantes. También, ha preparado a investigadores y profesionales de nivel superior en todos los campos. (p. 28)

A esta caracterización de la UNA debe sumarse su marcado enfoque humanista y su constante preocupación por atender, de forma solidaria, a poblaciones y realidades usualmente excluidas de los centros de poder y toma de decisiones, en donde innegablemente la academia tiene un papel preponderante.

En lo que respecta a la formación inicial de docentes, la Universidad Nacional dirige su atención, desde el CIDE, hacia los sectores donde se requieren docentes con compromiso con la equidad y la calidad educativa, por lo que, retomando el ejemplo de la Escuela Normal, fortalece el acceso y la igualdad de oportunidades entre su estudiantado, llevando la formación a las zonas más remotas del país y fortaleciendo su sistema de becas, condiciones que materializan el acceso genuino de sectores marginados a la educación superior. Por ello, la UNA se reconoce a sí misma como la Universidad Necesaria, por lo cual:

Garantiza que las oportunidades de estudio y de desarrollo integral que ofrece lleguen a todos los sectores de la sociedad costarricense. .... A esta oportunidad de acceso al estudio sin exclusiones se une el sello humanístico de la UNA. La orientación humanista y la visión de desarrollo integral que caracteriza a esta casa de estudios se refleja en la forma horizontal en que se relacionan alumnos, profesores y funcionarios administrativos, lo mismo que en las actividades extracurriculares que hacen que el estudiante se pueda sentir "en casa". (Universidad Nacional, s. f., párr. 3-5)

Durante cuatro décadas, la UNA se ha fortalecido como institución y, gracias al aporte de personal académico, estudiantes y personal administrativo, recibe reconocimiento por parte de personajes ilustres de la ciencia, la cultura y las humanidades; hecho de gran importancia para el país. Es imperativo resaltar que la enseñanza y el aprendizaje van de la mano con procesos culturales e históricos, en el contexto de cada estudiante y su carrera.

Aunque los tiempos han cambiado y con ello las formas de entregar la docencia, los orígenes de la Universidad Nacional siguen siendo inspiración para muchas personas que creen en la educación como elemento clave para el desarrollo del país, por lo que desde el CIDE se rescatan valores y experiencias que antaño fueron claves para la consolidación de nuestra sociedad. 
doi: http://dx.doi.org/10.15359/ree.20-1.21

URL: http://www.una.ac.cr/educare

CORREO: educare@una.cr

La escuela marca la vida de los alumnos, este es el espacio donde el docente contribuye a esa formación de una manera mental, física y espiritual. No se puede pasar por alto la influencia que el maestro ejerce de manera positiva o negativa; la persona que tiene la vocación de enseñar debe saber que su labor no termina en el aula. (León, 1982, p.108)

De esta manera, el enfoque social, interdisciplinario y humanista que caracterizó la escuela normal costarricense sigue vigente en la misión del CIDE, Centro encargado de la formación docente en la UNA:

El Centro de Investigación y Docencia en Educación contribuye con el mejoramiento cualitativo y continuo de la educación en los ámbitos institucional, nacional e internacional, para promover el desarrollo integral de las personas y la transformación social, mediante procesos de docencia, investigación, extensión y producción académica, fundamentados en el humanismo, la excelencia, la responsabilidad social y ambiental, la integridad, la equidad y la valoración de la diversidad. (CIDE, s. f., párr.1)

Así, si bien la actualidad reclama importantes transformaciones en todos los ámbitos, y particularmente en educación, la formación de docentes humanistas y con espíritu solidario continúa siendo una premisa fundamental y necesaria para la promoción de una sociedad equitativa; por ello, hay que decir que la Escuela Normal de Costa Rica respondió a las necesidades educativas del país y suplió de miles de maestros y maestras que inspiraron, formaron y tuvieron a su cargo las bases de la educación costarricense. Sin este reconocimiento, la historia educativa de nuestro país estaría incompleta.

En la actualidad, los principios humanistas que sobresalieron en aquella formación son recuperados y fortalecidos por la vida democrática universitaria y las prioridades de formación que la UNA sigue manteniendo vigentes, así como el espíritu voluntarioso que hoy caracteriza la formación inicial de docentes en el CIDE.

Por lo tanto, se puede afirmar, junto con Cordero (1998), que la Escuela Normal de Costa Rica "cumplió, en sus seis escasas décadas de existencia con los fines de su creación, lo más importante es que lo hizo con abundancia" (p. 30); tanto, que su legado le sobrevive. 


\section{Referencias}

Centro de Investigación y Docencia en Educación (CIDE). (s. f.). Misión. Recuperado de http:// www.cide.una.ac.cr/index.php?option=com content\&view=article\&id=54\&/temid=139

Charconnet, M.-G. (1975). La enseñanza mutual. Descripción funcional de sus distintos sistemas y aplicaciones. París: UNESCO. Recuperado de http://unesdoc.unesco.org/ images/0002/000236/023698SB.pdf

Cordero, J. A. (Noviembre, 1998). De la Escuela Normal a la Facultad de Educación de la Universidad de Costa Rica y al CIDE. Revista del Centro de Investigación y Docencia en Educación, 4, 29-35.

Dengo, M. E. (2013). El desarrollo de la formación docente en Costa Rica. En J. M. Salazar (Ed.), Historia de la educación costarricense (pp. 193-265). San José, Costa Rica: EUNED.

Escolano, A. (Enero-abril, 1982). Las escuelas normales, siglo y medio de perspectiva histórica. Revista de Educación, 269, 55-76. Recuperado de http://www.mecd.gob.es/dctm/revistade-educacion/articulosre269/re2690413059.pdf?documentld=0901e72b813cd44d

Figueroa, L.M.(2000). La formación de docentes en las escuelas normales: Entre las exigencias de la modernidad y las influencias de la tradición. Revista Latinoamericana de Estudios Educativos, 30(1), 117-142. Recuperado de http://www.cee.iteso.mx/BE/RevistaCEE/t 20001 05.pdf

Fischel, A. (2013). La educación costarricense: Entre el liberalismo y el intervencionismo. En J. M. Salazar (Ed.), Historia de la educación costarricense (pp. 73-116). San José, Costa Rica: EUNED.

Hernández, E. y Lobo, S. (1996). La Escuela Normal de Costa Rica y su influencia en la formación de maestros 1915-1940 (Tesis de licenciatura inédita). Universidad Nacional, Heredia, Costa Rica.

Homenaje de la Escuela Normal de Costa Rica a sus maestros graduados. (1933). San José, Costa Rica: Imprenta Nacional. Recuperado de http://historia.ucr.ac.cr/cmelendez/ handle/123456789/835

León, E. (1982). Una universidad en una ciudad de maestros. Heredia: Universidad Nacional.

Maya, C. O. y Zenteno, E. (Setiembre, 2003). Las escuelas normales: Espacios de tensión y controversia. Educación 2001, 100, 29-37.

Meléndez, C. (2001). Añoranzas de Heredia (2a ed.). Heredia, Costa Rica: EUNA. Recuperado de http://www.sinabi.go.cr/Biblioteca\%20Digital/LIBROS\%20COMPLETOS/Melendez\%20 Carlos/Anoranzas\%20de\%20Heredia\%20Completo.pdf 
doi: http://dx.doi.org/10.15359/ree.20-1.21

URL: http://www.una.ac.cr/educare

CORREO: educare@una.cr

Núñez, I. (Mayo, 2010). Las escuelas normales: Una historia de fortalezas y debilidades 1842-1973. Docencia 40, 32-39. Recuperado de http://www.revistadocencia.cl/ pdf/20100907015901.pdf

Rivera, L. M. (2012). Asamblea Legislativa de Costa Rica fomenta igualdad de oportunidades en la educación superior estatal: Aprobación de la Ley de Creación de la Universidad Nacional. Recuperado de http://www.asamblea.go.cr/Centro de informacion/Servicios Parlamentarios/Reseas\%20histricas/Creación\%20de\%20la\%20Universidad\%20Nacional. pdf

Salgado, R. U. (s. f.). La formación docente en la región: de las normales a las universidades. Recuperado de http://www.oei.es/docentes/articulos/formacion docente region normales universidades.pdf

Solera, G. (1965). Escuela Normal de Costa Rica en sus bodas de oro. Referencias biográficas de sus fundadores y directores durante los años 1915-1965. Heredia, Costa Rica.

Universidad Nacional (UNA). (s. f.). Reseña histórica. Recuperado de http://web.pz.una.ac.cr/ index.php/2015-05-01-15-52-12/2015-05-01-16-00-41/resena-historica

\section{Cómo citar este artículo en APA:}

Carvajal-Jiménez, V. y Ruiz-Badilla, S. (Enero-abril, 2016). Escuela Normal de Costa Rica: Historia y legado. Revista Electrónica Educare, 20(1), 1-18. doi: http://dx.doi.org/10.15359/ree.20-1.21

Nota: Para citar este artículo en otros sistemas puede consultar el hipervínculo "Como citar el artículo" en la barra derecha de nuestro sitio web: http://www.revistas.una.ac.cr/index.php/EDUCARE/index 